Leptin and Animal Communication - 1

\title{
Leptinergic Regulation of Vertebrate Communication Signals
}

\section{Mehrnoush Nourbakhsh-Rey ${ }^{\mathbf{1}}$ and Michael R. Markham ${ }^{\mathbf{1 , 2}}$}

${ }^{1}$ Department of Biology, University of Oklahoma, Norman OK 73019 USA

${ }^{2}$ Cellular \& Behavioral Neurobiology Graduate Program, University of Oklahoma, Norman, OK 73019, USA

\section{Corresponding author:}

Michael Markham

The University of Oklahoma

Department of Biology

730 Van Vleet Oval

Norman, OK 73019

email: markham@ou.edu

phone: 405-325-0321

fax: 405-325-6202

Manuscript word count: 3915 
Leptin and Animal Communication - 2

\begin{abstract}
Animal communication signals are regulated by multiple hormonal axes that ensure appropriate signal targeting, timing, and information content. The regulatory roles of steroid hormones and many peptide hormones are well understood and documented across a wide range of vertebrate taxa. Two recent studies have reported a novel function for leptin, a peptide hormone central to energy balance regulation: regulating communication signals of weakly electric fish and singing mice. With only limited evidence available at this time, a key question is just how widespread leptinergic regulation of communication signals is within and across taxa. A second important question is what features of communication signals are subject to leptinergic regulation. Here we consider the functional significance of leptinergic regulation of animal communication signals in the context of both direct and indirect signal metabolic costs. Direct costs arise from metabolic investment in signal production, while indirect costs arise from the predation and social conflict consequences of the signal's information content. We propose a preliminary conceptual framework for predicting which species will exhibit leptinergic regulation of their communication signals and which signal features leptin will regulate. This framework suggests a number of directly testable predictions within and across taxa. Accounting for additional factors such as life history and reproductive strategies will likely require modification or elaboration of this model.
\end{abstract}


Leptin and Animal Communication - 3

\section{Leptinergic Regulation of Vertebrate Communication Signals}

Animal communication signals are essential for survival and reproduction, but these signals also come with significant risks and costs (Bradbury and Vehrencamp 2011). Multiple hormonal axes coordinately regulate the targeting, timing, and information content of communication signals toward an optimized balance of signal costs and benefits, both for the sender and the receiver. Within this context, a rich history of research has revealed the many ways in which both steroid and peptide hormones regulate communication signals in accordance with long- and short-term environmental, social, and organismal conditions (Adkins-Regan 2005; Ball and Balthazart 2009; Gavassa et al. 2013).

Steroid hormones, including androgens, estrogens, and progestins all modulate animal communication signals in the context of aggression and courtship (Adkins-Regan 2005). Sex steroids play vital role in the vertebrate physiology of signal production including gestural signals during courtship and male-male competition (Doyle and Meeks 2018; Tobiansky and Fuxjager 2020). Additionally, sex steroids exert non-reproductive functions through regulating the timing and mechanisms of switching between sexual and nonsexual communication signals (Tobiansky and Fuxjager 2020). The time course of steroidal regulation is generally on the scale of days to weeks, thereby integrating external and internal cues over longer periods to guide appropriate behavior.

Peptide hormones regulate animal communication signals over shorter intervals through both central and peripheral mechanisms (Albers 2012; Markham et al. 2009a; Thompson et al. 2006; Wilczynski et al. 2017). The role of peptide hormones in social communication contexts is quite varied, but can be generally characterized as integrating immediate social and environmental conditions to produce short-term changes (minutes to hours) in communication 
appropriate for the immediate context. Importantly, the effects of steroid and peptide hormones are rarely independent of one another and are frequently interactive (e.g, Allee et al. 2009).

Here we focus on hormonal regulation of the metabolic costs incurred by communication signals, and potential hormonal mechanisms for balancing signal costs against the organism's metabolic state and current behavioral demands. Within any communication system, animals expend energy to gain information about their environments and communicate information to conspecifics. Understanding these energy-information tradeoffs is essential for understanding the constraints that shape animal sensory and communication systems (Nelson and MacIver 2006) and for revealing the principles that determine how animals balance the tradeoff of energetic investment and social information. Two recent studies have implicated the peptide hormone leptin as a new and perhaps essential hormonal factor for regulating animal communication in this context. Extending from these findings, we suggest a conceptual framework for expanding comparative investigations of leptinergic regulation in animal communication.

\section{Leptin Regulates Animal Communication Signals}

Leptin is a relatively recent discovery in the large and diverse family of peptide hormones (Campfield et al. 1995; Zhang et al. 1994). Following its discovery, the initial and intensive focus on leptin centered on its role in mammals as an adipostat (a "fat thermostat") that regulates appetite, metabolic rate and, ultimately, fat stores (Ahima and Osei 2004). Subsequent identification of the leptin peptide and leptin receptors in all major vertebrate classes led to a recent surge of comparative studies on leptin's physiological functions (Londraville et al. 2017). The emerging picture from these approaches is that leptin is universally involved in regulating organismal energetics, but its physiological roles across taxa are complex and extend far beyond regulation of adiposity (Londraville et al. 2014). A growing body of comparative studies on the 
Leptin and Animal Communication - 5

endocrinology of leptin in nonmammalian taxa have revealed that it can have profound effects on metabolic rate, thermogenesis, seasonality, development, reproduction, stress response, immunity, and behavior (Londraville et al. 2014). The majority of studies in nonmammalian models have been in teleost fish where the diversity of leptin functions appears to be much higher, with sometimes opposite effects in different teleost species (Deck et al. 2017; Delgado et al. 2017; Won and Borski 2013; Zhang and Gong 2018; Zhao et al. 2013). The complexity of leptin's effects in fish is potentially because species throughout the teleost lineage possess two leptin paralogs, leptin A and leptin B, (Deck et al. 2017; Londraville et al. 2017), providing a broader substrate for expansion of leptin's functionality.

Given the many ways that leptin regulates energy allocation, it should not be surprising that leptin also regulates animal communication signals, which can incur substantial metabolic costs. What is surprising is that, to date, only two lines of evidence have emerged showing that leptin regulates communication signals in accordance with the organism's metabolic state (Burkhard et al. 2018; Giglio and Phelps 2020; Sinnett and Markham 2015). These findings are made all the more interesting because they show that leptin plays this role in two vastly divergent vertebrate taxa: teleost fish and mammals, and that leptin exerts its effects on communication signals generated by surprisingly different physiological mechanisms: electric communication signals and auditory courtship vocalizations.

The weakly electric freshwater fish Eigenmannia virescens (Figure 1) generates metabolically costly electric organ discharges (EODs) to image their world and communicate with conspecifics. The EOD is a sinusoidal waveform with individual specific frequencies of 200 $\mathrm{Hz}-600 \mathrm{~Hz}$, produced by the summation of near simultaneous action potentials in the electric organ cells. During periods of restricted food availability, E virescens reduces EOD amplitude 
(EODa), and restores EODa over the course of 2-3 days when ad-lib feeding is resumed. This effect is mediated by leptin: administration of exogenous leptin restores EODa in food-deprived fish, but has no effect on EODa when fish are fed ad-libitum (Sinnett and Markham 2015). The role of leptin in this case is to proactively reduce energetic investment in signal amplitude food-deprived and well-fed fish show the same transient EODa increases to both social and pharmacological challenges.

Leptin also regulates communication signals in the Neotropical singing mouse, Scotinomys teguina (Figure 1). Both sexes produce audible songs, but male mice produce elaborate vocal advertisement calls consisting of lengthy series of high-frequency notes (Banerjee et al. 2019). Singing effort in males, measured as a compound variable of multiple song features, correlates with adiposity and circulating leptin levels (Burkhard et al. 2018) and experimental administration of exogenous leptin increases song effort (Giglio and Phelps 2020).
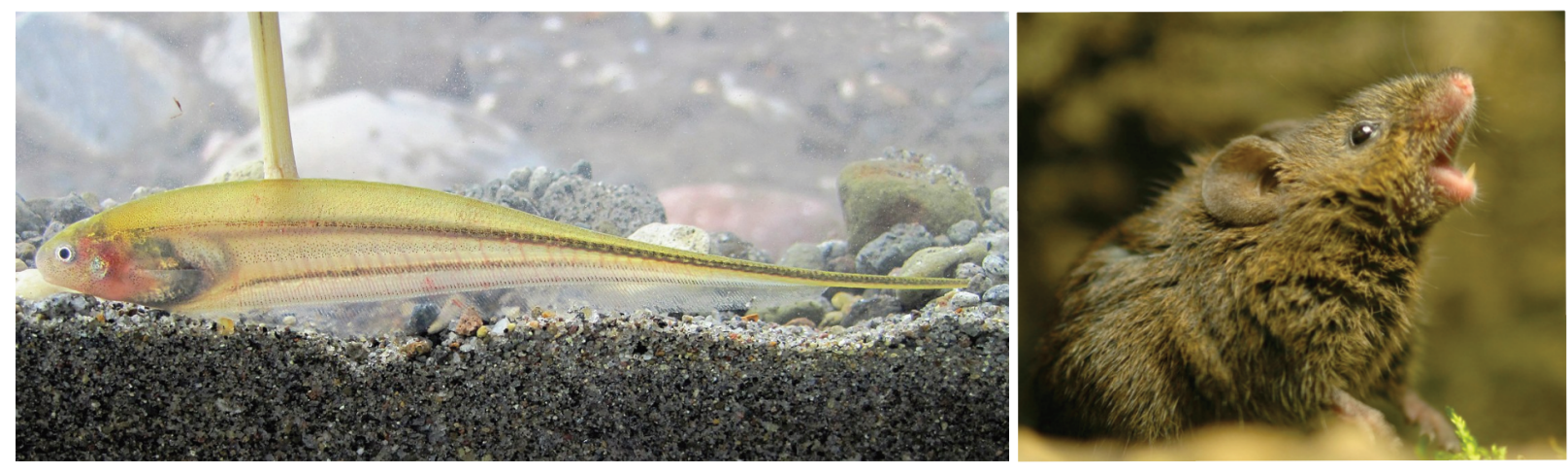

Figure 1. Two species where communication signals are regulated by leptin. (A) The weakly electric Glass Knifefish (Eigenmannia virescens) constantly generates electric sensory and communication signals that are sinusoidal waveforms with individual-specific frequencies of 200-600Hz. (Image courtesy of Ictiologia Universidad Católica de Oriente by Creative Commons license). (B) Allston's Singing Mouse (Scotinomys teguina): males sing complex songs consisting of a series of high-frequency notes (Image courtesy of Bret Pasch, Northern Arizona University).

In both cases, leptin appears to be a key factor that tunes communication performance in accordance the animal's prevailing metabolic state, suggesting that leptin might play a 
taxonomically broad role in regulating communication costs. The many known functions of leptin across taxa suggest that the primary function for leptinergic regulation of communication signals is specifically to reduce signal metabolic costs when energy reserves are low and promote metabolic investment in signaling when energy stores are high. In the case of animal communication signals, the total metabolic cost of signaling consists of multiple components. Discussions of metabolic costs associated with communication signals tend to focus on the direct metabolic investment in signal production (Dechmann et al. 2013; Ophir et al. 2010; Stoddard and Salazar 2011). However, animal communication signals also incur indirect metabolic costs including the costs of escaping or injury if a predator detects the signal, and the costs of conflict should the signal invite attack by a conspecific or interspecific rival (Bradbury and Vehrencamp 2011; Giglio and Phelps 2020).

These three cost components are influenced by particular combinations of signal features. The signal's amplitude, duration, and duty cycle will determine both its direct metabolic cost, as well as contribute to its indirect predation and conflict costs by increasing the likelihood of detection by predators and hostile rivals. The predation and conflict costs, however, are also influenced by the signal's information-coding components such as signal structure, patterning, or spectral content, features that can be varied independently of the signal's direct metabolic costs (Akçay et al. 2015; Gustison and Townsend 2015; Seyfarth et al. 2010). For example, a softlywhispered threat can still precipitate a very costly fight.

\section{A Preliminary Model for Investigating Leptinergic Regulation of Communication Signals}

Partitioning the metabolic costs of communication into direct and indirect costs suggests two interrelated predictions about when and how leptin will regulate communication signals. First, leptinergic regulation of communication signals should be favored when the combined 
Leptin and Animal Communication - 8

metabolic costs of signaling are highest. Second, the specific signal components regulated by leptin should reflect their contribution to the overall signal cost. Together these predictions suggest an initial three-dimensional framework for predicting when leptinergic signal regulation should be observed, and predicting which signal characteristics leptin will regulate (Figure 2). For signals that incur high direct metabolic costs but low predation or conflict costs, leptin should exclusively regulate signal amplitude, duration, and/or duty cycle. When signals incur low direct costs, but high indirect predation or conflict costs, the prediction is that leptin will regulate information-coding features of the signal. Finally, in the case of signals that carry both high direct and indirect costs, leptin should regulate both the information-coding features of the signal, as well as signal amplitude, duration, and/or duty cycle.

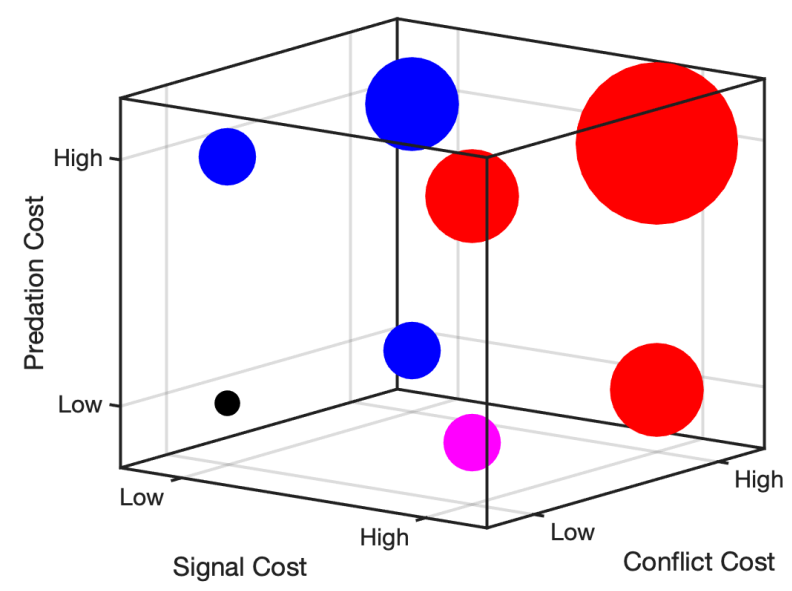

Figure 2. A proposed schematic framework for predicting when selective pressures will favor leptinergic regulation of communication signaling effort and/or signal information content. Circle size indicates total signal metabolic cost for each combination of cost parameters, and the corresponding adaptive advantage of leptinergic signal regulation. Circle color represents a prediction of which specific signal features should be targeted by lepinergic regulation: black = no regulation; magenta $=$ primary regulation of signaling effort; blue = primary regulation of information content; red = regulation of both signal effort and information content. 
Leptin and Animal Communication - 9

Given the limited data available, any conceptual framework or model for organizing leptinergic regulation of animal communication signals is bound to be an oversimplification, and additional experimental evidence will inevitably require elaboration and modification of the model. Nonetheless, our hope is that a preliminary framework such as this will point to a set of feasible experimental tests and serve as a springboard for a broader investigation of the adaptive functions and physiological mechanisms of leptinergic regulation in animal communication.

The initial evidence for leptinergic signal regulation in electric fish and singing mice is consistent with this framework, though very far from conclusive. Accordingly, a more detailed consideration and comparison of findings from these initial lines of evidence highlights a broad landscape of important and unanswered questions about the role that leptin plays in shaping these communication signals.

Direct signal costs for E. virescens are known to be quite high, and their ecology and habitat suggests that indirect predation and conflict costs also may be significant. Electric signal generation consumes a significant fraction (as much as $30 \%$ ) of the daily energy budget for $E$. virescens (Lewis et al. 2014; Salazar et al. 2013). The potential for conflict costs is also frequently present - this is a gregarious shoaling species where individuals regularly engage in courtship and agonistic interactions marked by transient frequency changes or interruptions of the electric signal (Hagedorn and Heiligenberg 1985; Hopkins 1974). These transient communication features, especially interruptions, introduce low-frequency spectral content (Hopkins 1974) that is detectable by sympatric electroreceptive predators (Stoddard and Markham 2008). The model we suggest here therefore predicts that leptin will regulate both the signal's direct and indirect costs. We indeed found that leptin regulates E. virescens' signal amplitude, a major component of the signal's direct and indirect metabolic cost (Sinnett and 
Leptin and Animal Communication - 10

Markham 2015). Our study, however, did not assess the effects of leptin on the transient information-coding features of the electric signal that occur during courtship and agonistic interactions, a clear area for future investigation.

In the case of singing mice, the potential for high indirect costs of communication is also present. Male vocalizations in S. teguina are associated with conspecific male-male aggression (Pasch et al. 2011) and can potentially invite interspecific aggression from a closely-related and larger species, S. xerampelinus (Pasch et al. 2013). The direct metabolic costs of these vocalizations has not been directly measured, but the long durations (4-7 s), duty cycle greater than $50 \%$, and high dominant frequencies $(>20 \mathrm{kHz})$ suggest a significant metabolic investment in vocalization. Several parameters of song production in male $S$. teguina are correlated with adipose stores and leptin titers (Burkhard et al. 2018), and these same song features are also regulated by exogenous leptin injections (Giglio and Phelps 2020). In this case, leptin regulated multiple information-coding song features including the song frequency (number of songs during the testing interval), song duration, and number of notes per song. Interestingly, some of these features changed in ways expected to increase direct metabolic cost (song frequency) while others changed in a manner expected do decrease direct metabolic cost, such as song duration and notes per song. Technical barriers precluded measurement of song amplitude, a centrally important component of direct metabolic cost. Though leptin's effects on direct song costs are not yet precisely known, these findings do suggest that leptin regulates direct costs and they clearly support a role for leptin in controlling the song's informational content. 
Leptin and Animal Communication - 11

\section{Expanding the Comparative Scope}

In the context of understanding leptin's full effects on signal costs, we are left with two intriguing but incomplete pictures from these studies. A complete comparison of leptin's functions in electric fish and signing mice would be aided by examining the effects of leptin on the indirect information-coding costs of electric signals in weakly electric fish, and the effects of leptin on the direct metabolic investment in singing by mice. To expand from these initial studies to a broader understanding of leptinergic signal regulation, additional comparative studies in other taxa are critically important. Most informative will be comparisons within and between taxa subject to different direct and indirect signal costs.

Given the broad diversity of signal characteristics, ecologies, and life histories across more than 200 species of freshwater Gymnotiform fish, comparative studies examining the effects of direct and indirect signal costs on leptinergic signal regulation could prove especially fruitful in this system. With species-specific signal frequencies ranging from $\sim 10 \mathrm{~Hz}$ to more than $2000 \mathrm{~Hz}$ and a wide range of signal amplitudes across species, the direct costs of signal generation should vary considerably across species. Similarly, the broad geographic and habitat distribution of these species provides variation in pressure from electroreceptive predators, and species-specific social structures range from fiercely solitary to gregarious and shoaling, thereby offering variation in signal conflict costs. The outcome variables of interest in electric fish are easily tractable and can be reliably measured. Precisely calibrated measurements of signal amplitude can be readily recorded from freely-swimming fish in the laboratory (Stoddard et al. 2003), and continuous recordings of electric signaling in social groups over many days is possible (Tallarovic and Zakon 2002), even in natural stream settings (Henninger et al. 2018; Madhav et al. 2018). Additionally, straightforward respirometry methods can be used 
Leptin and Animal Communication - 12

concurrently with electric signal recordings to directly measure the metabolic costs of signal production (Lewis et al. 2014; Salazar and Stoddard 2008).

Similar advantages are possible through comparative studies in avian and anuran species as well. The direct metabolic costs of signaling for several species of passerine birds are known, as is the case for at least six species of frog. In both cases signal costs vary over more than an order of magnitude (Stoddard and Salazar 2011) and detailed data on many species' social structure and predation risk are available. Informative comparisons are also possible in experimentally-accessible mammalian models. Sonic and/or ultrasonic communication is now documented in several murine species, and in many cases the social functions of these vocalizations are now well understood (e.g., Holy and Guo 2005). The combination of social manipulations with respirometry and calibrated signal analyses should allow a comparative examination of leptin's role in regulating vocalizations across species with different direct signal costs, different social conditions, and under different predation pressures.

\section{Additional Factors Beyond the Initial Model}

A simplified framework such as we outline here is almost certain to require significant revision and/or elaboration as additional data become available, particularly as the breadth of comparative studies increases. Two additional factors that will likely need to be incorporated into any model of leptinergic signal regulation are differences in life history, and the apparent differences in the physiological functions of leptin between major vertebrate taxa.

Life History Strategies One comparison between experimental findings from two species of electric fish suggests that leptin may not regulate signal amplitude for all species. In the weakly electric pulse fish Brachyhypopomus gauderio, food restriction does not reduce the baseline EODa, and food-restricted males actually produce larger transient increases in EODa 
Leptin and Animal Communication - 13

during social challenges than well-fed fish (Gavassa and Stoddard 2012). While this study did not test the effects of leptin on EOD characteristics, the failure of food restriction to impact EODa certainly implies that leptin does not regulate EODa in B. gauderio, a prediction that awaits experimental analysis.

Two sensible interpretations might explain why food availability (and presumably leptin) would regulate EODa in E. virescens, but not in B. gauderio. The first interpretation is consistent with the framework we have suggested: differential direct investment in signal production. The daily metabolic costs of EOD production in weakly electric fish studied to date is quite high in general, but the fraction of the daily energy budget devoted to EOD production is much higher for E. virescens than for B. gauderio (Lewis et al. 2014; Markham et al. 2016; Salazar and Stoddard 2008). A major reason for this difference is that B. gauderio produces EODs at variable rates of $10-100 \mathrm{~Hz}$ and can slow EOD rate to conserve energy if necessary. E. virescens, on the other hand, generates EODs at unvarying individually-specific rates of 200-600 Hz. Perhaps the adaptive value of regulating signal amplitude in accordance with metabolic state only selects for mechanisms of leptinergic signal regulation in species where signaling costs are sufficiently high. Additional comparative studies across weakly electric species with different EOD frequencies such as suggested earlier would provide a straightforward avenue for evaluating this possibility.

A second hypothesis is that different EODa responses to metabolic stress in E. virescens and B. gauderio are a result of differences in life history and reproductive strategy. E. virescens are iteroparous multi-season breeders (Hagedorn and Heiligenberg 1985; Kirschbaum 1979; Kramer 1987) whereas B. gauderio are semelparous single-season breeders (Silva et al. 2003). Iteroparous species typically reduce reproductive efforts (including costly communication 
Leptin and Animal Communication - 14

signals) during stressful periods, presumably to survive until environmental conditions improve before resuming reproductive efforts (Wingfield and Sapolsky 2003). Semelparous species typically continue reproductive behaviors during periods of stress, in some cases engaging in terminal investments in reproduction (Cluttonbrock 1984). Thus, E. virescens may reduce EODa to conserve energy and await better food availability while $B$. gauderio responds to dietary energy shortfalls with a terminal investment in reproduction. Again here, comparative studies across multiple electric fish species with different reproductive strategies would enable a direct test of whether leptinergic regulation of electric communication signals is indeed a function of reproductive strategy. This seems a distinct possibility, and one that would require an extension or revision of the initial model we have proposed here.

\section{Taxonomic Divergence in Leptin's Functions Outside the realm of animal} communication, leptin appears to function very differently across vertebrate taxa, with major differences in leptin's roles between mammalian, teleost, amphibian, and avian species (Copeland et al. 2011; Londraville et al. 2017). The classical view of leptin as an adipostatic hormone is consistent with the bulk of data for mammals and amphibians, whereas the functional roles of leptin have significantly diverged and diversified in fish and birds (Londraville et al. 2017). Thus, the role that leptin plays (or does not play) in regulating communication signals may not be general across all taxa. However, the fact that the first two instances where leptinergic regulation of communication was identified included mice and fish suggests the possibility that leptinergic regulation of communication signals could be taxonomically widespread. Whether the extent or nature of leptinergic signal regulation is similar or divergent across taxa is a matter that depends on continued investigation. 
Leptin and Animal Communication - 15

\section{Convergence and Divergence in the Physiology of Leptinergic Signal Regulation}

It is clear from existing evidence that leptin exerts its effects through both common and divergent mechanisms across taxa. For instance, the primary source of leptin in mammals is adipose tissue, whereas adipocytes contribute little or no leptin in teleosts. Instead, the highest levels of leptin expression in teleosts are from liver, with some expression also in brain, gonads, muscle, and kidney (Deck et al. 2017; Londraville et al. 2014; Won and Borski 2013). These differences are potentially important because tissue-specific sources of circulating leptin (i.e., adipocytes vs. liver) will determine the conditions under which leptin titers change and thereby determine which internal or external cues elicit leptinergic regulation of communication signals. For example, if leptin is exclusively released by adipocytes, then it will probably only regulate communication in response to changes in fat stores. In contrast, gonadal, hepatic, or central release of leptin would be expected to regulate communication in response to a wider range of internal and external cues.

It is also important to understand the common and diverse physiological mechanisms through which leptin regulates communication signals. Social communication signals represent the combined contributions of central control networks and peripheral effector tissues. Leptin is known to exert effects both on central neural and hormonal systems as well as regulating the physiology of peripheral tissues. Leptin is therefore likely regulating direct and indirect costs through the combined regulation of central mechanisms controlling signal investment and information coding, as well as the peripheral effector tissues that control the pattern, amplitude, and spectral content of signal output.

The observed effects of leptin on song structure and effort in singing mice certainly depend on regulation of the well-characterized central neural networks and motor pattern 
Leptin and Animal Communication - 16

generators that sequence and execute the song components (Okobi et al. 2019). This foundational knowledge sets the stage to examine the central mechanisms through which leptin controls song frequency, structure, and effort. It would be interesting to find out whether leptin also regulates peripheral effectors such as the laryngeal and expiratory musculature to further control signal metabolic costs. Similarly, central networks controlling electric signaling have also been defined to varying degrees in several species of electric fish (Comas et al. 2019; Perrone and Silva 2018; Silva et al. 2013) highlighting the possibility of mechanistic studies investigating leptinergic control over information-coding patterns of electric signaling.

In weakly electric fish, peripheral mechanisms of signal modulation in the electrocytes play a key role in controlling both the direct metabolic costs of communication (Markham et al. 2016), and the signal's spectral characteristics which encode important social information (Gavassa et al. 2013). Our recent data have shown that the muscle-derived electric organ cells (electrocytes) in E. virescens express membrane-bound leptin receptors that colocalize the with electrocyte's voltage-gated $\mathrm{Na}^{+}$channels (unpublished observations). These findings indicate that leptin regulates EODa, at least in part, by acting directly on the electrocytes - perhaps to control the magnitude of the electrocytes voltage-gated $\mathrm{Na}^{+}$currents, a known mechanism for regulating EODa in this species (Markham et al. 2013). We are also exploring the possibility that leptin also regulates EODa by interacting with centrally-regulated hormonal axes that regulate pituitary melanocortin hormones that control EODa in E. virescens and closely-related electric fish species (Markham et al. 2009a; Markham et al. 2013; Markham et al. 2009b). Currently, the strikingly common situation for singing mice and electric fish is the presence of extensive and accessible uncharted territory for exploring how and why leptin regulates their communication signals. 
Leptin and Animal Communication - 17

\section{Conclusion}

Perhaps the greatest challenge for all organisms is to secure sufficient metabolic resources and effectively allocate their limited energy reserves across the many competing physiological functions essential for survival and reproduction. Leptinergic regulation of communication is one mechanism for achieving an adaptive balance of energy expenditure weighted against the costs and benefits of communication. At this time, however, available experimental data are too limited to allow any informed speculation about how widespread leptinergic regulation is within and across taxa. The exact functional nature of leptinergic signal regulation is also not fully known, nor are the physiological mechanisms for these actions. Continued comparative and integrative investigations in these areas are centrally important to discover the rules that govern how animals balance tradeoffs between energetic investment and social information. 
Leptin and Animal Communication - 18

\section{Referenes}

Adkins-Regan E. 2005. Hormones and animal social behavior. Princeton: Princeton University Press.

Ahima RS, Osei SY. 2004. Leptin signaling. Physiol Behav. 81(2):223-241.

Akçay Ç, Anderson RC, Nowicki S, Beecher MD, Searcy WA. 2015. Quiet threats: soft song as an aggressive signal in birds. Anim Behav. 105:267-274.

Albers HE. 2012. The regulation of social recognition, social communication and aggression: vasopressin in the social behavior neural network. Horm Behav. 61(3):283-292.

Allee SJ, Markham MR, Stoddard PK. 2009. Androgens enhance plasticity of an electric communication signal in female knifefish, Brachyhypopomus pinnicaudatus. Horm Behav. 56(2):264-273.

Ball GF, Balthazart J. 2009. Endocrinology of animal communication: Behavioral. In: Squire LR, editor. Encyclopedia of Neuroscience. Oxford: Academic Press. p. 981-989.

Banerjee A, Phelps SM, Long MA. 2019. Singing mice. Curr Biol. 29(6):R190-R191.

Bradbury JW, Vehrencamp SL. 2011. Principles of animal communication. Sunderland, Mass.: Sinauer Associates.

Burkhard TT, Westwick RR, Phelps SM. 2018. Adiposity signals predict vocal effort in Alston's singing mice. Proc Biol Sci. 285(1877).

Campfield LA, Smith FJ, Guisez Y, Devos R, Burn P. 1995. Recombinant mouse OB protein: evidence for a peripheral signal linking adiposity and central neural networks. Science. 269(5223):546-549. 
Leptin and Animal Communication - 19

Cluttonbrock TH. 1984. Reproductive effort and terminal investment in iteroparous animals. Am Nat. 123(2):212-229.

Comas V, Langevin K, Silva A, Borde M. 2019. Distinctive mechanisms underlie the emission of social electric signals of submission in Gymnotus omarorum. J Exp Biol. 222(Pt 11).

Copeland DL, Duff RJ, Liu Q, Prokop J, Londraville RL. 2011. Leptin in teleost fishes: An argument for comparative study. Frontiers in Physiology. 2.

Dechmann DKN, Wikelski M, Van Noordwijk HJ, Voigt CC, Voigt-Heucke SL. 2013. Metabolic costs of bat echolocation in a non-foraging context support a role in communication. Frontiers in Physiology. 4.

Deck CA, Honeycutt JL, Cheung E, Reynolds HM, Borski RJ. 2017. Assessing the functional role of leptin in energy homeostasis and the stress response in vertebrates. Frontiers in Endocrinology. 8:63.

Delgado MJ, Cerda-Reverter JM, Soengas JL. 2017. Hypothalamic integration of metabolic, endocrine, and circadian signals in fish: Involvement in the control of food intake. Front Neurosci. 11:354.

Doyle WI, Meeks JP. 2018. Excreted steroids in vertebrate social communication. J Neurosci. 38(14):3377-3387.

Gavassa S, Goldina A, Silva AC, Stoddard PK. 2013. Behavioral ecology, endocrinology and signal reliability of electric communication. The Journal of Experimental Biology. 216(13):2403-2411.

Gavassa S, Stoddard PK. 2012. Food restriction promotes signaling effort in response to social challenge in a short-lived electric fish. Horm Behav. 62(4):381-388. 
Leptin and Animal Communication - 20

Gibala MJ, MacLean DA, Graham TE, Saltin B. 1997. Anaplerotic processes in human skeletal muscle during brief dynamic exercise. J Physiol (Lond). 502(3):703-713.

Giglio EM, Phelps SM. 2020. Leptin regulates song effort in Neotropical singing mice (Scotinomys teguina). Anim Behav. 167:209-219.

Gustison ML, Townsend SW. 2015. A survey of the context and structure of high- and lowamplitude calls in mammals. Anim Behav. 105:281-288.

Hagedorn M, Heiligenberg W. 1985. Court and spark - Electric signals in the courtship and mating of gymnotoid fish. Anim Behav. 33(Feb):254-265.

Henninger J, Krahe R, Kirschbaum F, Grewe J, Benda J. 2018. Statistics of natural communication signals observed in the wild identify important yet neglected stimulus regimes in weakly electric fish. J Neurosci. 38(24):5456-5465.

Holy TE, Guo Z. 2005. Ultrasonic songs of male mice. PLoS Biol. 3(12):e386.

Hopkins CD. 1974. Electric communication: Functions in the social behavior of Eigenmannia virescens. Behaviour. 50(3/4):270-305.

Kirschbaum F. 1979. Reproduction of the Weakly Electric Fish Eigenmannia virescens (Rhamphichtyidae, Teleostei) in Captivity .1. Control of Gonadal Recrudescence and Regression by Environmental-Factors. Behav Ecol Sociobiol. 4(4):331-355.

Kramer B. 1987. The Sexually Dimorphic Jamming Avoidance-Response in the Electric Fish Eigenmannia (Teleostei, Gymnotiformes). Journal of Experimental Biology. 130:39-62.

Lewis JE, Gilmour KM, Moorhead MJ, Perry SF, Markham MR. 2014. Action potential energetics at the organismal level reveal a trade-off in efficiency at high firing rates. $\mathrm{J}$ Neurosci. 34(1):197-201. 
Leptin and Animal Communication - 21

Londraville RL, Macotela Y, Duff RJ, Easterling MR, Liu Q, Crespi EJ. 2014. Comparative endocrinology of leptin: Assessing function in a phylogenetic context. Gen Comp Endocrinol. 203:146-157.

Londraville RL, Prokop JW, Duff RJ, Liu Q, Tuttle M. 2017. On the molecular evolution of leptin, leptin receptor, and endospanin. Frontiers in Endocrinology. 8.

Madhav MS, Jayakumar RP, Demir A, Stamper SA, Fortune ES, Cowan NJ. 2018. Highresolution behavioral mapping of electric fishes in Amazonian habitats. Sci Rep. $8(1): 5830$.

Markham MR, Allee SJ, Goldina A, Stoddard PK. 2009a. Melanocortins regulate the electric waveforms of gymnotiform electric fish. Horm Behav. 55(2):306-313.

Markham MR, Ban Y, McCauley AG, Maltby R. 2016. Energetics of sensing and communication in electric fish: A blessing and a curse in the Anthropocene? Integr Comp Biol. 56(5):889-900.

Markham MR, Kaczmarek LK, Zakon HH. 2013. A sodium-activated potassium channel supports high-frequency firing and reduces energetic costs during rapid modulations of action potential amplitude. J Neurophysiol. 109(7):1713-1723.

Markham MR, McAnelly ML, Stoddard PK, Zakon HH. 2009b. Circadian and social cues regulate ion channel trafficking. PLoS Biol. 7(9):e1000203.

Nelson ME, MacIver MA. 2006. Sensory acquisition in active sensing systems. J Comp Physiol, A. 192(6):573.

Okobi DE, Jr., Banerjee A, Matheson AMM, Phelps SM, Long MA. 2019. Motor cortical control of vocal interaction in neotropical singing mice. Science. 363(6430):983-988. 
Leptin and Animal Communication - 22

Ophir AG, Schrader SB, Gillooly JF. 2010. Energetic cost of calling: general constraints and species-specific differences. J Evol Biol. 23(7):1564-1569.

Pasch B, Bolker BM, Phelps SM. 2013. Interspecific dominance via vocal interactions mediates altitudinal zonation in neotropical singing mice. Am Nat. 182(5):E161-173.

Pasch B, George AS, Hamlin HJ, Guillette LJ, Jr., Phelps SM. 2011. Androgens modulate song effort and aggression in Neotropical singing mice. Horm Behav. 59(1):90-97.

Perrone R, Silva AC. 2018. Status-dependent vasotocin modulation of dominance and subordination in the weakly electric fish Gymnotus omarorum. Front Behav Neurosci. $12: 1$.

Salazar VL, Krahe R, Lewis JE. 2013. The energetics of electric organ discharge generation in gymnotiform weakly electric fish. J Exp Biol. 216(Pt 13):2459-2468.

Salazar VL, Stoddard PK. 2008. Sex differences in energetic costs explain sexual dimorphism in the circadian rhythm modulation of the electrocommunication signal of the gymnotiform fish Brachyhypopomus pinnicaudatus. J Exp Biol. 211(Pt 6):1012-1020.

Seyfarth RM, Cheney DL, Bergman T, Fischer J, Zuberbühler K, Hammerschmidt K. 2010. The central importance of information in studies of animal communication. Anim Behav. 80(1):3-8.

Silva A, Quintana L, Galeano M, Errandonea P. 2003. Biogeography and breeding in Gymnotiformes from Uruguay. Environmental Biology of Fishes. 66(4):329-338.

Silva AC, Perrone R, Zubizarreta L, Batista G, Stoddard PK. 2013. Neuromodulation of the agonistic behavior in two species of weakly electric fish that display different types of aggression. The Journal of Experimental Biology. 216(13):2412-2420. 
Leptin and Animal Communication - 23

Sinnett PM, Markham MR. 2015. Food deprivation reduces and leptin increases the amplitude of an active sensory and communication signal in a weakly electric fish. Horm Behav. $71: 31-40$.

Stoddard PK, Markham MR. 2008. Signal cloaking by electric fish. Bioscience. 58(5):415-425. Stoddard PK, Markham MR, Salazar VL. 2003. Serotonin modulates the electric waveform of the gymnotiform electric fish Brachyhypopomus pinnicaudatus. J Exp Biol. 206(Pt 8):1353-1362.

Stoddard PK, Salazar VL. 2011. Energetic cost of communication. J Exp Biol. 214(Pt 2):200205.

Tallarovic SK, Zakon HH. 2002. Electrocommunication signals in female brown ghost electric knifefish, Apteronotus leptorhynchus. Journal of Comparative Physiology A, Sensory, Neural, and Behavioral Physiology. 188(8):649-657.

Thompson RR, George K, Walton JC, Orr SP, Benson J. 2006. Sex-specific influences of vasopressin on human social communication. Proceedings of the National Academy of Sciences. 103(20):7889-7894.

Tobiansky DJ, Fuxjager MJ. 2020. Sex steroids as regulators of gestural communication. Endocrinology. 161(7).

Wilczynski W, Quispe M, Muñoz MI, Penna M. 2017. Arginine vasotocin, the social neuropeptide of amphibians and reptiles. Frontiers in Endocrinology. 8.

Wingfield JC, Sapolsky RM. 2003. Reproduction and resistance to stress: when and how. J Neuroendocrinol. 15(8):711-724.

Won ET, Borski RJ. 2013. Endocrine regulation of compensatory growth in fish. Frontiers in Endocrinology. 4:74. 
Leptin and Animal Communication - 24

Zhang J, Gong M. 2018. Review of the role of leptin in the regulation of male reproductive function. Andrologia.

Zhang Y, Proenca R, Maffei M, Barone M, Leopold L, Friedman JM. 1994. Positional cloning of the mouse obese gene and its human homologue. Nature. 372(6505):425-432.

Zhao Z-J, Zhu Q-X, Chen K-X, Wang Y-K, Cao J. 2013. Energy budget, behavior and leptin in striped hamsters subjected to food restriction and refeeding. PLOS ONE. 8(1):e54244. 
Leptin and Animal Communication - 25

\section{Acknowledgements}

We extend our sincere thanks and gratitude to Julie Butler and Karen Maruska for their tireless and outstanding work in organizing the 2021 symposium where this work was presented, "Sending and Receiving Signals: Endocrine Modulation of Social Communication." Preparation of this manuscript was supported by NSF grants IOS1350753 and IOS1644965 (MRM), and by the Case-Hooper endowment, funded through a gift from Dr. and Mrs. Robert Case to The University of Oklahoma. 
Leptin and Animal Communication - 26

Figure Captions

Figure 1. Two species where communication signals are regulated by leptin. (A) The weakly electric Glass Knifefish (Eigenmannia virescens) constantly generates electric sensory and communication signals that are sinusoidal waveforms with individual-specific frequencies of 200 $-600 \mathrm{~Hz}$. (Image courtesy of Ictiologia Universidad Católica de Oriente by Creative Commons license). (B) Allston's Singing Mouse (Scotinomys teguina): males sing complex songs consisting of a series of high-frequency notes (Image courtesy of Bret Pasch, Northern Arizona University).

Figure 2. A proposed schematic framework for predicting when selective pressures will favor leptinergic regulation of communication signaling effort and/or signal information content. Circle size indicates total signal metabolic cost for each combination of cost parameters, and the corresponding adaptive advantage of leptinergic signal regulation. Circle color represents a prediction of which specific signal features should be targeted by lepinergic regulation: black= no regulation; magenta $=$ primary regulation of signaling effort; blue $=$ primary regulation of information content; red = regulation of both signal effort and information content. 